\title{
A STUDY ON THE OPTIMIZATION METHOD FOR PANEL LAYOUT PROBLEM IN DRYWALL
}

\author{
Kosei Ishida* and Naruo Kano \\ School of Creative Science and Engineering, Waseda University, Tokyo, Japan \\ *Corresponding author (vrsoturon@yahoo.co.jp)
}

\begin{abstract}
This study is aimed at developing methods to optimize the material yield of drywall panels. In this paper, the authors describe the drywall panel layout optimization method which consists of the following three steps: first, to generate possible alternative patterns of drywall panel layout in a wall; second, for each alternative pattern, to find out the best combination of panel parts to be cut from a panel of standard size; third, to solve the cutting length of panels, the waste volume of panels and the length of panel joints in each layout pattern.

The authors applied this method to minimize the cost of drywall using plaster board $(1820 \times 910 \mathrm{~mm})$. The method generates possible patterns of drywall panel layout in the wall and acquires the best combination of panels to be cut from a standardsize panel, then estimates the cost of drywall works in each pattern.
\end{abstract}

Keywords: Drywall, Optimization Problem, Yield Loss, Plaster Board, Cutting Stock Problem

\section{Introduction}

The drywall consists of studs and gypsum boards. To minimize the cost of the drywall, it is important that the drywall is installed in the minimum number of boards and the waste of gypsum boards should be reduced.

This study is aimed at developing methods to optimize the material yield of drywall panels.

\section{Optimization method for panel layout problem in drywall}

The authors developed the following optimization method for panel layout problem in drywall. The drywall panel layout optimization method consists of the following three steps.

1) To generate possible alternative patterns of the drywall panel layout in a wall

2) For each alternative pattern, to find out the best combination of panel parts to be cut from a panel of standard size

3) To solve the cutting length of panels, the waste size of panels and the length of panel joints in the each pattern.

The authors define following terms in this paper.

Drywall field: Drywall field is a wall or a ceiling surface.

The shape is polygon.
Rectangle: In this paper, "Rectangle" is a sheet material, for example a gypsum board. The sheet material is manufactured in metric size.

Polygon: In this paper, "Polygon" is a sheet material cut to the shape of the wall.

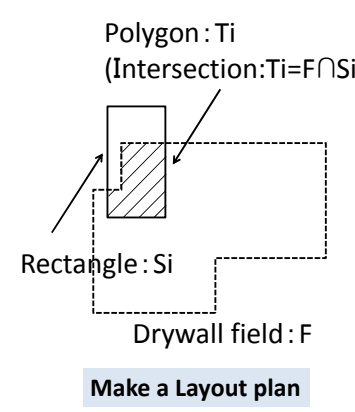

Waste materials : $\mathrm{Zi}$
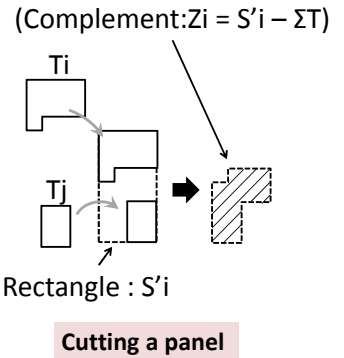

Fig.1 Make layout plan and cutting a panel

To plan drywall panel layout in a wall, $\mathrm{n}$ items (small "Rectangles") $\mathrm{S}=(1,2, \ldots \mathrm{n})$ and one object(drywall field) $\mathrm{F}$ are given. It is required to place the items orthogonally without any overlap. Then, "Rectangles" are cut to the shape of the wall. The cut "Rectangles" is "Polygon". "Polygon" is an intersection of two sets "Rectangle" and "Drywall field". $(\mathrm{Ti}=\mathrm{F} \cap \mathrm{Si})$

When the authors intended to create and optimize a cutting plan, the authors places a given set of $\mathrm{n}$ items(small 
polygons) $\mathrm{T}=(1,2, \ldots \mathrm{n})$ into objects(rectangles) $\quad \mathrm{S}^{\prime}$ $=(1,2, \ldots, \mathrm{m})$ without overlap so as to minimize the waste of gypsum boards.

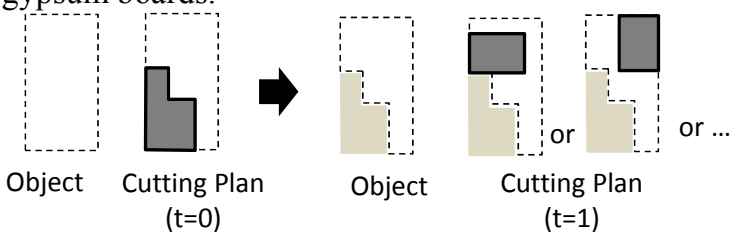

Fig.2 Placement of the small polygons into the rectangle

\section{Development and application of an optimization} system to minimize the waste of drywall using plaster board

The authors developed an optimization system and applied this system to minimize the waste of drywall using plaster board $(1820 \times 910 \mathrm{~mm})$ for a wall shown in Fig.3. All the apexes of the wall (Drywall field) are the rightangle. The authors hang the panels (rectangles) horizontally or vertically. T(i) have all the polygons .

1) To choice a start point.

2) To put a rectangle panel the start point horizontally (or vertically) and the other panels are put a straight joint.

3) To make a cutting plan

The method of making a cutting plan in this system consists of the following five steps, where T(i) is an item set of the polygons composing a panel layout.

1) If $T(i)$ includes the rectangle which is manufactured in metric size, the system remove the rectangle from $\mathrm{R}(\mathrm{i})$.

2) The system calculates each area of the polygons.

3) The system generates all combinations of two or more polygons. The sum of the areas of a polygon set must be less than the area of the rectangle which is manufactured in metric size.

4) The system chose a set which is the largest sum of the areas and then put set of the polygons into the rectangle.

5) If the system can put set of the polygons into the rectangle, the system remove the polygons from $\mathrm{T}(\mathrm{i})$ and then returns to (2). If the system can't put a set of the polygons into the rectangle, the system chose a set which is the next biggest sum of the areas and returns (4). If the system can't put all sets of polygons into the rectangle, the system finishes.
Fig.4 shows examples of some plaster board layouts horizontally. Fig.5 shows the results of the optimization layouts horizontally and vertically.

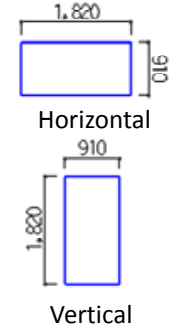

$$
\text { Plaster board }
$$
(Rectangle)

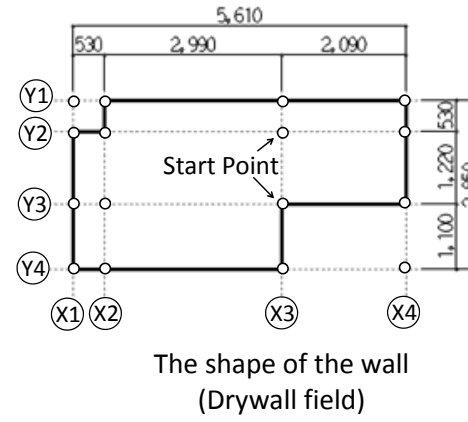

Fig.3 Plaster board and the shape of the wall

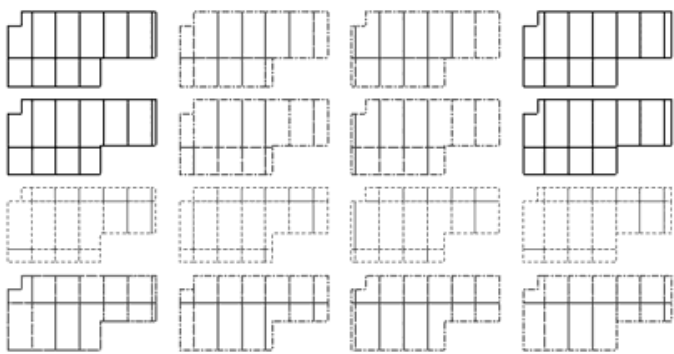

Fig.4 Examples of some plaster board layouts
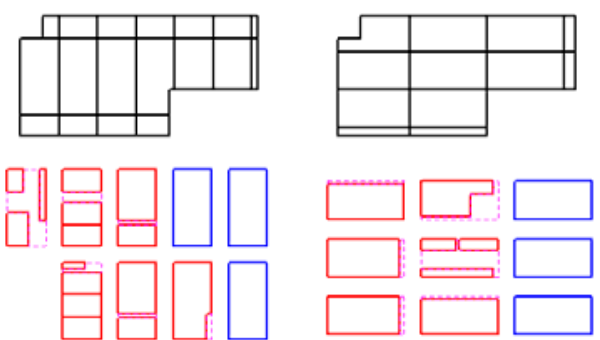

Fig.5 Optimization layouts horizontally and vertically

\section{Conclusion}

The authors applied the system to minimize the waste of drywall using plaster board successfully. However, if the wall is large to generate too many combination of panel layout patterns, the computing time increases exponentially. Further study is needed to consider the methods to reduce the number of combinations.

\section{REFERENCES}

[1] S. Imahori, M. Yagiura and H. Nagamochi: Practical algorithms for two-dimensional packing, in T. F. Gonzalez (ed.), Handbook of Approximation Algorithms and Metaheuristics, Chapman \& Hall/CRC, Boca Raton, 2007 